\title{
Social Software and Strategy
}

\section{Stefan Haefliger, Eric Monteiro, Dominique Foray and Georg von Krogh}

Social software challenges strategic thinking in important ways: empowering creative, independent individuals implies indeterminate and uncertain reactions and creations in support of, or in opposition to, management's original thinking. We build a framework that organizes research on social software, taking perspectives from both inside and outside companies. We use this framework to introduce the contributions to this special issue in terms of strategy, technology, and community and to ask a series of questions for strategy research that pays particular attention to value creation and appropriation, the role of technology both as tool and mediator between managers and users, and the role that management can play in communities, both as leaders and in shaping boundaries.

(c) 2011 Elsevier Ltd. All rights reserved.

\section{Introduction}

Aligning interests, motivating contributions to knowledge work, and giving direction to multiple business units and market initiatives represent daily challenges for the strategist in most companies. The diversity of contexts within an organization has led critical management thinkers to suggest that in the presence of multiple initiatives and discourses, the introduction of a new technology has multiple unintended consequences for organization. New technology is regularly subject to power struggles, conflicting goals, and discrepant events (Markus, 1983; Barley, 1986; Orlikowski, 1992; Ciborra, 1996; Leonardi, 2008) which impact on how strategies are shaped within organizations.

Information technology, such as social software, may affect the interaction patterns between organizational members, create new opportunities for knowledge and information sharing (von Krogh, 2002), or unfold the disruptive and possibly change-inducing potential of so called "informational capabilities" (Leonardi, 2007). Informational capabilities refer to an information technology's potential to alter the storage, transmission, and creation of information in an organization. In this respect information and communication technology (ICT) differs from other technologies adopted by organizations. Despite the broad application of ICT and its potential implications 
for company performance (Powell and DentMicallef, 1997; Tippins and Sohi, 2003; Ho et al., 2011), strategy scholars seldom include the properties of ICT in their theorizing on strategic thinking, firm growth and its boundaries, or the strategies for creating ICT infrastructure (Leidner et al., 2010; Yoo et al., 2010).

The term "social software" grew out of the notion of groupware and computer-supported collaborative work (CSCW) and had been attributed to Clay Shirky, who denoted software that supports group interaction (Allen, 2004; Shirky, 2005). Designed to facilitate individual creativity combined with community building, groupware and social software have led, in their 1.0 incarnation, to novel and significant insights in academic fields ranging from technological innovation, organizational behavior, and management and organization theory, to strategy (Sproull and Kiesler, 1986; Sawhney and Prandelli, 2000; Lee and Cole, 2003; von Krogh and von Hippel, 2006). Today, social software, frequently annotated with Web or Enterprise 2.0, also receives a lot of interest from managers due to its commercial use, increased network functionality, massive mobilization of users in some cases, and growing infrastructure capabilities, such as multi-media streaming online. ${ }^{1}$ The more than enthusiastic reception of LinkedIn by investors during their initial public offering in May 2011 suggests that the commercial promise of a business model involving large numbers of users connected through social software inspires investors: secondary market valuations of companies such as Facebook, Groupon, or Twitter are interpreted along similar lines or else discounted as signs of market participants' exuberance.

Social software affects the interaction between employees within and individuals outside the firm, such as members of user communities or customers. In many industries, users of technology, frequently organized in communities, are known to innovate independently of manufacturers (von Hippel, 1988; 2007), and consumers have successfully contributed to innovation and product development organized by firms (Füller et al., 2010; Franke et al., 2010). A perspective that privileges firminternal matters, which the strategy field has often tended to adopt (Mintzberg, 1978), risks overlooking the increasingly powerful and important position that individuals outside the firm hold, particularly when organized in communities (Fredberg, 2009; Dahlander and Wallin, 2006). Here, users and customers set up the governance structures for their communities independently of firms (Markus, 2007; O'Mahony and Ferraro, 2007), often voice criticism toward firms and their products (Kaplan and Haenlein, 2010; Kozinets and Handelman, 2004; Muniz and O'Guinn, 2001), or develop rival products in existing markets (Casadesus-Masanell and Ghemawat, 2006; Young and Rohm, 1999). Hence, in terms of strategic analysis, users and consumers can be "suppliers," "competitors," or "providers of substitutes," as shown in the examples of widely used Open Source software (OSS) programs like Apache servers or the GNU Linux operating system.

Social software enables the activities of people inside and outside companies actively to shape strategies. The papers in this special issue offer novel, strategic insights on this subject. Social software thus holds an intriguing potential. As consistently demonstrated over the last couple of decades, the actual realization of this potential is anything but straightforward. This special issue unites authors who have gained deep insights into the workings of user communities, their technologies, and the strategic potential that collaborations between firms and communities harbor, in terms of value creation and appropriation. This introductory article contributes to an overall positioning of the papers, drawing on the literatures from fields such as strategy, ICT, technology studies, and innovation. In so doing, we also develop a research agenda on social software that we hope will inspire strategy scholars to continue work in this important area.

Social software creates platforms for self-expression (Schau and Gilly, 2003) and direct interaction between individuals and so facilitates rapid and often spontaneous community building (Culnan et al., 2010). Social software also enables interaction between online consumers and users, their product development efforts (Füller et al., 2010), their mutual rating of ideas and comments (Haefliger et al., 2009), and provides online community members with a basic infrastructure for

\footnotetext{
${ }^{1}$ For the original definition of Web 2.0 see O'Reilly, 2005. Wirtz et al. (2010: 276) characterize Web 2.0 with four factors: social networking, interaction orientation, personalization/customization, and user-added value.
} 
their work (Lee and Cole, 2003; Ren et al., 2007; Kohler et al., 2011). Thus, social software becomes an exciting topic for strategy practitioners and scholars. If social software supports management in harnessing the creative output of individuals inside and outside the firm, the deployment and diffusion of such technology may hold considerable business potential. The video game industry, for example, experiences rapid growth thanks to social software platforms (such as Facebook, which has more than 500 million registered users) that serve as alternatives to consoles and enable online gaming involving competition among friends connected through such platforms. ${ }^{2}$

At the same time, the "harnessing" metaphor often employed by companies interacting with communities may be problematic. It might very well suggest too much firm influence. The connotations of control embedded in the metaphor need to be supplemented or even substituted by stronger aspects of cultivation and facilitation. Evidence for successful interaction between firms and user communities is scarce (e.g. Stam, 2009; Stuermer et al., 2009), despite frequently high investments by firms in such collaboration (Dahlander and Wallin, 2006). IBM, for example, invested significant resources into the public development of their Eclipse software development platform for a duration of five years, before development by outside software users outweighed IBM's own development efforts (Spaeth et al., 2010). There are three major implications resulting from the use of social software that favors a broader view of collaboration, extending beyond the company. First, users can assume several strategically important roles for the company beyond their obvious role as consumers of products and services. Most notably, they may supply ideas for product development (see Fuchs and Schreier, 2011), and may offer competing products, as is the case for OSS (see von Hippel, 2007). Second, social software shares with all information technology the capacity to change organizations in unpredictable ways, because it directly alters the way and the location where information is stored, shared, and created (Kling and Scacchi, 1982; Markus, 1983; Leonardi, 2007; 2008). The fact that most "outside members" of social software platforms are unknown to the firm makes it even harder to foresee how ICT will change the organization. Third, users rely on social software to organize within online communities that may or may not be supported by companies, and "develop a life of their own" (Wiertz and de Ruyter, 2007: 390). Understanding which interventions by the company will be perceived as beneficial or obtrusive is key to building lasting relationships with members of such platforms (Jeppesen and Frederiksen, 2006). In the software industry, IBM received credit for their efforts to support the OSS community, whereas Sun Microsystems (now Oracle) was widely criticized for their hesitation to release the source code for Java, the cross-platform programming language (West and Gallagher, 2006; Vaughan-Nichols, 2009).

These three implications build a framework, which we present in the next section, which organizes research on social software, taking perspectives from both inside and outside companies. We use this framework to locate the contributions to this special issue in terms of strategy, technology, and community. Later, we use the framework to highlight open issues for strategy research building on the contributions by authors in this issue.

\section{Toward a framework}

Social software has been in use in firms for a number of years but standard or best practice ways of applying social software are not yet visible. Managers and researchers alike still struggle with questions, such as why and how to interpret social software, what are shared perceptions, how to appropriate potential business value, when to enact work practices involving social software, and where to align it with other business processes. For example, the usefulness of social software as an internal communication device is up for debate (see Denyer et al., 2011). Moreover, the perception of Facebook as a platform to do business is changing the gaming industry. Finally, aligning internal software development efforts with external community development creates new challenges for design science (von Krogh and Haefliger, 2010).

\footnotetext{
${ }^{2}$ For example, Zynga, the producer of games such as FarmVille, is valued at US\$10 billion and is thus significantly higher than, e.g., the game industry incumbent Electronic Arts (US\$7.5 billion) according to the Wall Street Journal (February 19, 2011). And while $90 \%$ of all users play for free, $10 \%$ of the 250 million users reliably pay small amounts for in-game assets and enhancements.
} 
The role of information and communication technology in organizations has been the focus over decades of research (Markus and Robey, 1988; Leonardi and Barley, 2010). Early organizational theorists considered technology to have a unidirectional impact on organizations, forcing management to change some aspect of the organization according to the contingencies inherent in the material features of the technology (Perrow, 1967). This perspective was later challenged by social constructivists who focused instead on the members of the organization who responded to the technology's constraints and to each others' use of the technology (for a review, see Leonardi and Barley, 2010), as well as on the material features of the technology and its role as an actor in organizations (Orlikowski and Scott, 2008; Wagner et al., 2010). This highlights the inherently unintended consequences of technology, which undermine its overly instrumental "deployment" (Rolland and Monteiro 2007). It is this active role of ICT as a mediator between individuals in organizations and between intended and completed actions that complicate strategic deployment and adoption of ICT in firms, even more so when individuals outside and frequently unknown to the company play an important role.

The study of social software in terms of its strategic implications needs to accelerate, since many companies are far advanced with experiments connecting individuals inside and outside the company. At the same time, strategy research should broaden the narrow perspective of authoritative decisions about technology adoption that might miss the influential role technology plays outside the direct control of management. With this special issue and this framework we attempt to follow both suggestions. More specifically, we suggest issues for future research to build on a balanced perspective that takes into account what management can and should influence, combined with an appreciation of consumers' and users' work outside the firm. Two observations about social software may help strategy scholars understand the connection between the perspectives from inside and outside the firm. First, social software shapes the behavior of individuals during evaluation, adoption, early use, and adaptation. Second, and closely connected to the first point, it enables individuals inside and outside the firm to appropriate features of the technology in ways unintended by management or the technology's designers (Markus and Silver, 2008; DeSanctis and Poole, 1994). The case of LEGO (Hienerth et al., 2011) shows how the adoption of social software enabled a business model where customers co-create new products and commercialize them on the LEGO platform. In the process LEGO had to overcome significant organizational and psychological barriers including the fear of losing control. Stuermer et al.'s (2009) study of Nokia's development of the Open Source Maemo platform reached a similar conclusion.

There are a number of recent contributions in strategy and organization theory that have addressed issues involving social software in the domains of strategy, technology, and community. Table 1 presents the proposed framework and the research published in this special issue. The table distinguishes work that takes a view from inside the company, and studies that focus on similar issues outside the firm. Rather than aiming at an extensive review of this literature, we focus below on distinctive characteristics of the two views that are relevant for understanding the strategic dynamics social software can help generate. First, research that bridges the two perspectives has emerged in the management of innovation (Lamastra, 2009; Fuchs and Schreier, 2011; Capra et al., 2011), but less so in strategy, management, and organization theory (O'Mahony and Bechky, 2008). The articles brought together in this issue bridge the insights that emerge from studying managerial intentions as well as user and consumer behavior inside and outside the firm. Studies limited to a view from outside the firm may bear little business relevance and studies limited to a view from inside the firm may ignore activities by (sometimes unknown) outsiders with significant potential impact on strategy and new business models.

\section{Strategy}

Thirteen years ago, Jeffrey Sampler (1998: 349) was already proposing that the availability of critical information for the same market defines industry boundaries, rather than what strategy scholars' considered an industry; firms delivering comparable or similar outputs. Thanks to the free exchange of information over the Internet and the access to social software applications, information that 


\begin{tabular}{|c|c|c|c|}
\hline & VIEW FROM INSIDE THE FIRM & $\begin{array}{l}\text { SPECIAL ISSUE } \\
\text { CONTRIBUTORS }\end{array}$ & VIEW FROM OUTSIDE THE FIRM \\
\hline Strategy & Implement & & Emergence \\
\hline \multirow[b]{2}{*}{$\begin{array}{l}\text { Value } \\
\text { appropriation }\end{array}$} & $\begin{array}{l}\text { Inviting and empowering customers to } \\
\text { contribute to product development (Fuchs \& } \\
\text { Schreier, 2010) }\end{array}$ & $\begin{array}{l}\text { Burger-Helmchen } \\
\text { and Cohendet }\end{array}$ & $\begin{array}{c}\text { Strategic interaction with other users (Kuk, } \\
\text { 2006) and learning benefits (Lakhani \& von } \\
\text { Hippel, 2003) }\end{array}$ \\
\hline & $\begin{array}{l}\text { Firms' differentiated involvement in } \\
\text { communities, dual licensing (Dahlander, 2007), } \\
\text { selective revealing (Henkel, 2006), better } \\
\text { innovation performance (Stam, 2009) }\end{array}$ & $\begin{array}{l}\text { Hienerth, Keinz, } \\
\text { and Lettl }\end{array}$ & $\begin{array}{l}\text { Availability and dissemination of assets under } \\
\text { Open Source and Creative Commons licenses } \\
\text { (Lerner \& Tirole, 2005), or appropriation by } \\
\text { user entrepreneurship (Haefliger et al., 2010) }\end{array}$ \\
\hline Technology & Deploy & & Self-expression \\
\hline \multirow[t]{2}{*}{$\begin{array}{l}\text { Social software } \\
\text { as a tool }\end{array}$} & $\begin{array}{l}\text { Gaining access to creative users, utilizing their } \\
\text { judgement and their know-how (Füller et al., } \\
\text { 2010) }\end{array}$ & $\begin{array}{c}\text { Denyer, Parry, and } \\
\text { Flowers }\end{array}$ & $\begin{array}{l}\text { Use of blogs and community participation for } \\
\text { self-expression (Schau \& Gilly, 2003) and } \\
\text { identity building (Muniz \& O'Guinn, 2001, } \\
\text { Kozinets, 2002) }\end{array}$ \\
\hline & $\begin{array}{l}\text { Platform-induced biases (Dellarocas and } \\
\text { Wood, 2008), groups and user-generated } \\
\text { content and behavior as "runtime } \\
\text { effect" (Shirky, 2005; Cooke \& Bukley, 2008) }\end{array}$ & $\begin{array}{l}\text { Frey, Lüthje, and } \\
\text { Haag }\end{array}$ & $\begin{array}{c}\text { Technology architecture signals value (Baldwin } \\
\& \text { Clark, 2006) and suggests (self-) assignment } \\
\text { of tasks and specialization (Yamauchi et al., } \\
\text { 2000; von Krogh et al., 2003) }\end{array}$ \\
\hline Community & Harness & & Belonging \\
\hline Leadership & $\begin{array}{l}\text { Trade-offs between community founding and } \\
\text { sponsorship (West \& O'Mahony, 2005; Shah, } \\
\text { 2006), community leadership costly and } \\
\text { complex (Spaeth et al., 2010) }\end{array}$ & $\begin{array}{l}\text { Sutanto, Tan, } \\
\text { Battistini, and } \\
\quad \text { Phang }\end{array}$ & $\begin{array}{l}\text { Central role of most achieved members of the } \\
\text { community (Moon \& Sproull, 2001; Raymond, } \\
\text { 1999), social skills matter beyond technical } \\
\text { savvy (O'Mahony \& Ferraro, 2007) }\end{array}$ \\
\hline Boundary & $\begin{array}{c}\text { Cultural differences as challenge (Pauleen \& } \\
\text { Yoong, 2001), risk of knowledge leakage } \\
\text { (Hustad \& Teigland, 2008) }\end{array}$ & $\begin{array}{l}\text { Jarvenpaa and } \\
\text { Lang }\end{array}$ & $\begin{array}{l}\text { Firm involvement makes a difference in terms } \\
\text { of contribution and motivation (Shah, 2006; } \\
\text { Stewart et al., 2006) yet firm recognition } \\
\text { matters (Jeppesen and Fredriksen, 2006) }\end{array}$ \\
\hline
\end{tabular}


assumes a strategic importance for a market may be available to individuals inside or outside companies. This information may include insights into customer preferences as they are shared in social networks, ideas for new products and services, or information about available substitutes. On the one hand, research on consumer and user communities in the areas of marketing and user innovation focused on a view outside the firm, and showed that consumers and users build communities and organize to achieve specific goals (Muniz and O'Guinn, 2001; Moon and Sproull, 2000; O'Mahony, 2003; Wiertz and Ruyter, 2007). On the other hand, strategy research looked inside the firm to approach the question of how firms can make use of consumer and user communities in the creation and appropriation of value. The results from implementing social software here, however, either tend to be focused on specific positive cases or provide inconclusive results (da Cunha and Orlikowski, 2008, see also Denyer et al., 2011). Moreover, the growing literature on open innovation tends to confine the exchange with external parties, such as suppliers or users, to identifiable and manageable knowledge (Chesbrough, 2003), such as research papers, information about patents or instruments, or to one-directional search in a space of technological opportunities (Laursen and Salter, 2006; Jeppesen and Lakhani, 2010). An exception can be found in new product development, where firms have started successfully to empower customers to interact among themselves (Fuchs and Schreier, 2011). Using social software in its simpler (1.0) versions, firms have successfully appropriated value from implementing strategies targeted at collaborating with OSS development communities (Henkel, 2006; Dahlander, 2007) as well as modding communities in the video game industry (Arakji and Lang, 2007). However, so far only Stam (2009) has conclusively linked collaboration with Open Source communities with innovation performance. Frequently, the argument in the literature is that devoting resources to collaboration strategies with user communities would only be beneficial if their contribution paid off for the firm (von Hippel and von Krogh, 2003; Dahlander and Wallin, 2006).

A view from outside the company suggests that social software generates value for individuals because it facilitates interaction with and learning from other consumers and users, helps to build shared identity, and enables joint creation and shaping of technology for own use (Lakhani and von Hippel, 2003; Kuk, 2006, Hertel et al., 2003). Initially, so-called "commons-based peer production" relied on users who connected and exchanged information through a set of rather simple social software tools such as email lists, Internet relay chat, and message forums (Benkler, 2002; Lee and Cole, 2003). While the technology became more sophisticated (2.0), the communities spread and grew: individuals perceived value in collaboration and continued to exchange information in online communities (Ren et al., 2007). Meanwhile, much of the value generated is free and publicly available (including posts in online forums and OSS) and consumers and users take measures to protect this value (O’Mahony, 2003), such as non-profit incorporation, social norms of collaboration, and legal refinement (e.g. licenses under which OSS is made available). Licenses are designed to keep access to information and technology as open as desirable or possible, and they include creative commons and various Free and Open Source software licenses (Lerner and Tirole, 2005, Lang et al., 2009). Furthermore, users turn entrepreneurs by learning from industry experts and recruiting through a network enabled by social software (Haefliger et al., 2010).

The first contribution to this special issue by Burger-Helmchen and Cohendet provides guidelines and examples of how companies in the video game industry foster special relationships with community members outside firm boundaries, in order to gain insights and creative output from collaborating with closely bound and loyal customers. The authors classify communities and their members in order to understand better appropriate firm action to improve the relationships with communities; co-creation of value is a fragile process that depends on motivation and mutual trust. The second contribution by Hienerth, Keinz and Lettl explores the characteristics of user-centered business models, building on well-known cases such as LEGO and IBM. A core contribution lies in identifying successful strategies for integrating users into essential business processes and overcoming internal resistance. The authors elaborate how these processes enable the appropriation of value as part of a new user-centered business model. The paper by Jarvenpaa and Lang compares two distinct platform ownership strategies for supporting content co-creation, using 
real cases from the music industry. They find that both firm-based and community-based platform ownership designs present viable strategies. The authors suggest that firm-based platform ownership strategies are associated with a moderate level of openness (in terms of content and community membership) and are most effective when importance is granted to the coherence of the co-created content output and opportunities (for community members) to express identity. Communitybased platform ownership strategies, on the other hand, are most suitable when novel content and opportunities (for community members) to develop competence are critical.

\section{Technology}

ICT is a management tool but, at the same time, it harbors a deeply disruptive potential for organizational change that should not be underestimated. Users inside and outside companies attribute meaning to the functionality offered by a technology that can alter the identity of a technological artifact, such as a search platform or a discussion forum (Faulkner and Runde, 2009), change work practices such as information seeking (Leonardi, 2007), or, as Shirky (2005) puts it, result in a "runtime effect" of ICT. Analogous to software, certain characteristics of the program become apparent as a runtime effect: only after an ICT system is installed and used, can we discern its real impact on the organization. Bridging economics and management, Brynjolfsson and Saunders (2009) discuss evidence of the key ways in which firms have transformed the firm, supplier relations, and the customer relationships by combining IT with changes in work practices, strategy and products and services. Case studies and econometric work point to organizational complements-such as novel business processes, skills, and organizational structures - as major drivers of the contribution of information technology. The management literature often uses suggestive wording about "harnessing" and "utilizing" users' creative thinking. Management scholars have frequently adopted a perspective on ICT as a tool for gaining access to users' creative output (e.g. Füller et al., 2010). Less often, authors have focused on the biases and novel forces social software introduces when mediating and organizing work. For example, Dellarocas and Wood (2008) demonstrated the impact of online trading platforms on the interaction between users in a way that resulted in massively overstated user satisfaction. In a study on market research, social software is shown to have the potential to generate insights, due to the links it enables between consumers, whose commenting and rating behavior introduces quality judgments and points to trends (Cooke and Buckley, 2008). In these examples, social software mediates between individuals' activities and collective outcome in ways that are limiting or enabling.

Users perceive social software as a tool for creative expression and identity building online (Schau and Gilly, 2003; Muniz and O'Guinn, 2001). Visibility and peer recognition motivate consumers and users to share their personal experiences with products and companies, and even lead to the development of sub-cultures with specific vocabularies, creative expressions, and behavior (Kozinets, 2002). Conversely, users are shaped by social software, the architecture of digital artifacts, and the specific practices of collaboration that surround and build these artifacts. According to Baldwin and Clark (2006) the architecture of a software can be understood in terms of "option value" where collaboration and contributions to its development are guided by the user's perceived rewards in terms of progress and recognition. For example, users are known to self-select into tasks for a collaborative project in OSS development (Yamauchi et al., 2000) and the specialization of labor in projects follows the logic of an evolving and growing technology implementation (von Krogh et al., 2003). Hence, there are strong links between the architecture of an ICT system and user behavior, including where and to what part of the technology users choose to contribute, how they collaborate and communicate, or even when and where they choose to free-ride on what other users provide.

Contributors to this special issue approach the technology of social software from a strategic perspective, paying particular attention to the motivations and reservations of individuals inside and outside the firm. The article by Denyer, Parry, and Flowers documents the effort to deploy social software within a large telecommunications company. Their story is one of disappointment relative to the high-flying promises of openness and participation. The authors find that the solution 
implemented did not achieve positive outcomes relative to more traditional methods of communication. The authors offer valuable insights into political processes, such as monitoring and self-promotion, which may have contributed to the dismal reception of the new technology. They show that the problems uncovered do not lie with the technology but with the behavior of users, who need to find a delicate balance of power between the organization's leaders and employees. The contribution by Frey, Lüthje, and Haag studies a search platform for innovative ideas. Social software takes the form of a mediator between individual contributors and firms performing broadcast search on the platform. The authors suggest that deploying such a platform leads to more substantial contributions, when it succeeds in attracting intrinsically motivated individuals with diverse knowledge backgrounds. Both these contributions engage with technology and lead the authors to caution strategists in being too ambitious towards social software and urging them to take users' perspectives and motivations seriously.

\section{Community}

Social software is an integral part of the formation of online communities; it enables individuals, who may not be previously linked, to interact and socialize. Part of the strategist's fascination with social software stems from the possibility of accessing a pool of voluntary contributors to strategy, products, services, and business models, who are qualified, motivated, and productive. Realizing this potential requires influence, which is not easy to gain. Dan Frye, Vice President of OSS at IBM, commented on IBM's work with the Eclipse community (quoted in Kerner, 2010): “There is nothing that we can do to control individuals or communities, and if you try, you make things worse. What you need is influence. It goes back to the most important lesson, which is to give back to the community and develop expertise. You'll find that if your developers are working with a community, that over time they'll develop influence and that influence will allow you to get things done."

The question is, what strategic actions toward facilitating community interaction are possible, for whom, and at what stage (Thompson 2005)? Leadership in an online community is fragile because gaining influence takes years of commitment and investment (Spaeth et al., 2010) and the involvement of companies may change community members' motivation (Shah, 2006; Stewart et al., 2006). For example, companies must decide whether to found a community or to sponsor an existing community (West and O'Mahony, 2005). Both options involve trade-offs with regard to control, influence, and costs. Users may look beyond the deployment of social software to consider joining existing social networks that span across and beyond companies. Thus, it becomes important to understand the governance structures of online communities in order to appreciate the differences and potential risks when applying leadership practices established in a corporate context (Markus, 2007; O’Mahony and Ferraro, 2007). Leadership in user communities is thought to emerge from a meritocracy where technical achievement and boundary spanning is rewarded with power (Fleming and Waguespack, 2007). O'Mahony and Ferraro (2007) drew a refined picture by showing that technical skill alone does not lead to powerful positions: social skills of mediation and negotiation among community members predict future leaders more reliably (see also Fleming and Waguespack, 2007; Collier et al., 2010).

Community boundaries form around individuals, frequently volunteers, who "interact over time around a shared purpose, interest, or need" (Ren et al., 2007: 378). Beyond a general understanding of the risks in social software, such as "knowledge leakage" (e.g. Hustad and Teigland, 2008), the current strategy literature offers little guidance for firms on how to manage community boundaries. Central questions involve the selection, joining, and adherence to norms in existing communities and how this relates to staffing, task allocation, or business process involvement. Professional communities play an important role in the early stages of alliance formation (Rosenkopf et al., 2001) but comparable research on online communities is largely lacking. A potential recourse for strategy scholars may be the literature on virtual teams, which emphasizes the role of facilitators and cautions about the risk inherent in spanning different cultural contexts (e.g. Pauleen and Yoong, 2001; Martins et al., 2004). This risk may grow when linking corporate and non-corporate contexts. 
The practice of setting up mechanisms to protect intellectual property reveals that users, like companies, are concerned about losing control over their work (O'Mahony, 2003). However, users often operate in a context of private-collective innovation outside a corporate hierarchy and without labor contracts that regulate their contributions to the community or company (von Hippel and von Krogh, 2003). Because of this, researchers have devoted comparatively more attention to the motivation of users with respect to community boundaries than to leadership issues involving the firm. The motivation to contribute to the community seems to be affected by whether or not companies are involved and sponsor the community (Shah, 2006; Stewart et al., 2006), and the extent to which the firm explicitly credits and recognizes users' contributions (Jeppesen and Frederiksen, 2006).

Two contributions in this special issue deal explicitly with the interactions between firm and community. Sutanto, Tan, Battistini, and Phang test a model of emergent leadership in a setting where users interact and develop network ties. The model predicts perceived leadership from the interaction patterns of users and may provide strategists with specific insights and potential levers about companies interacting with user communities. The work by Jarvenpaa and Lang focuses on boundary management in platform-based online communities by taking a holistic perspective on platform owners and users who form communities. Based on findings from a case study that compares a firm-sponsored fan community and an autonomous community of practice in the domain of digital music remix, they discuss the interactions and interdependencies among organizational boundaries and tradeoffs between openness and control. They argue for integrated management of power, identity, competence, and efficiency boundaries as a necessary condition for achieving community goals and managing what the authors call the "generative capacity" of online communities - that is, their ability to create and innovate content around the members' shared purpose.

This special issue on social software assembles works that span perspectives inside and outside the firm by studying topics of relevance to strategy and placing the emphasis on the role of consumers and users. Next, we build on these contributions by formulating an agenda for future research.

\section{Open issues for strategy research}

There are several open issues regarding social software that deserve the attention of strategy scholars. Many of them start with a practical appreciation of the business implications of this technology: practical technologies for recruiters may help human resource management refine their frameworks for talent management and succession planning; new ways of storing, accessing, and locating patient data may bring about not only personalized medicine but also changes in health management systems; best practices of compensating resourceful users boost new product development initiatives.

Generally, strategic management is concerned with issues like firm survival, the allocation of resources across business units, or the creation of novel business models. In what areas other than those treated in this special issue does social software impact on these questions, and how? To begin exploring this question, it is worth considering the larger ramifications of social software. While refined definitions of social software may moderate or limit disruptive effects to specific business processes, the logic builds on what Leonardi (2007) termed informational capabilities of information technology. Organizations need to grapple with fundamentally indeterminate effects when introducing social software at many levels. The idea of a "runtime effect" of social software (Shirky, 2005) is analagous to the role the system environment plays in the execution of a software program. Adoption, use, and adaptation of a new technology, such as social software, provide contexts in which organizational actors define what a technology means and what it can do for them before and during action (see Leonardi and Barley, 2010 for a review). Hence, the "management" of social software becomes an ongoing task that incorporates the user's role and adapts strategy according to negotiation and structuring of work. Against this background, we develop a series of questions for strategy research that pays particular attention to value creation and appropriation, the role of technology both as tool and mediator between managers and users, and the role that management can play in communities, both as leaders and in shaping boundaries. Table 2 contains the questions evoked by the framework. 
Table 2. Open research issues for strategy research and social software

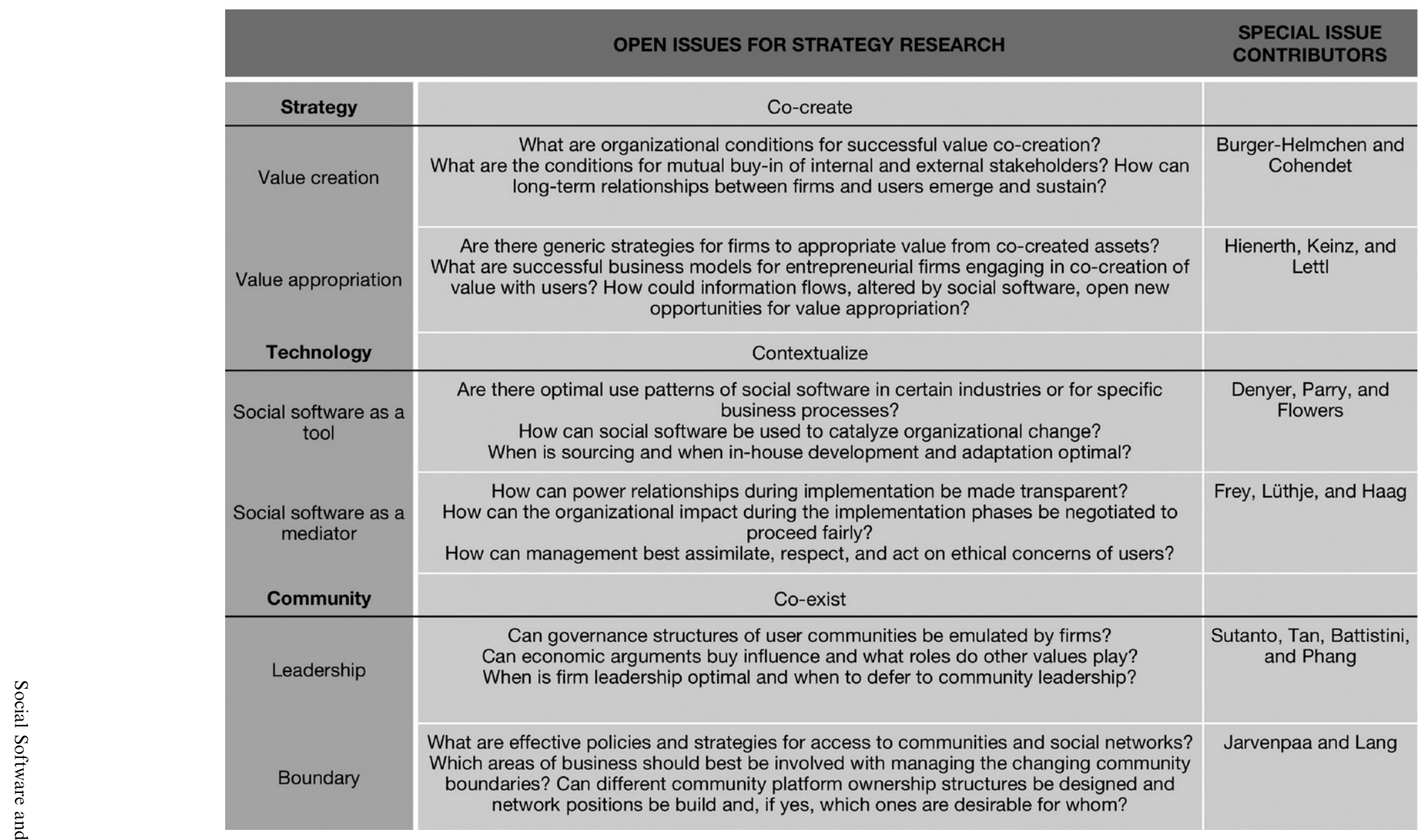




\section{Co-creation and appropriation of value}

The creation of economic value involving consumers and users connected through social software may depend on organizational structures that support their work. These individuals may or may not be members of the same organization. Yet, the new links between individuals, the exchange of information, and the potential to adhere to the norms of such a network may generate opportunities for knowledge sharing and joint work inside an organization that could be very valuable, or even disruptive to existing ways of creating value. The first question regarding organizational structure touches upon fundamental issues in strategy: which parts of the hierarchy remain intact and which may change? How might social software impact on formal and informal organizations and their interaction? How are decision rights allocated among members in business processes with open networks and free flows of information? Who has the authority to interact with external users? What are the "hidden costs" of changes in organization structure?

The issue of value creation has an important time component, in that co-creation between firms and outside consumers and users involves building trust, providing mutual support, and bearing joint questioning. If social software is to grant access to members from outside the company, the meaning of a "common purpose" may change. Some consumers show extraordinary loyalty to brands and products over a long period of time. Creating a shared purpose relating to a brand or a product could be a productive way of activating value co-creation. This may be costly and time-consuming-and the question of what supports mutual buy-in remains open to research. In their seminal study, Jeppesen and Frederiksen (2006) showed that explicit recognition of outside contributions had a positive impact on value creation.

Value appropriation requires relatively exclusive access to an asset or complementary assets from which products or services can be derived. The growth of business models that contain some "free" elements, and the use of advertising to collect revenue (McGrath, 2010), indicate that appropriating value from user-generated content may become easier. However, the creative commons family of licenses may lead to the growth of the number of domains where appropriation of others' work becomes less straightforward, and companies can no longer count on unsuspecting users who, sometimes ignorantly, pass on the rights to their intellectual property (von Hippel, 1988). With the growing awareness of intellectual property infringements, we also expect more public awareness of ownership. The creative commons movement actively educates users about their rights and advocates their making a conscious choice about how to license creative work. ${ }^{3}$ Based on their study of music remix communities that have adopted creative commons content licenses, Jarvenpaa and Lang (2011) argue that sustainable community-based participation in deeper forms of co-creation practices - that is, creating multi-generational product derivatives-requires new, nonlinear kinds of authorship certification. In particular, they point to the incorporation of software-automated attribution trees into the creative commons license design as a possible solution to recognizing complex authorship structures and providing an incentive for community members to continue to contribute content to co-creation communities (in the example of cultural goods). In software, OSS licenses limit the possibility of users and firms appropriating the rights to software components for re-sale. Important works by Henkel (2006); Dahlander (2007) and Dahlander and Magnusson (2008) have classified a series of strategic approaches to this difficulty encountered by software companies.

Future research may uncover generic patterns in business models that take advantage of assets co-created with consumers and users. The work by Hienerth and colleagues in this issue takes a major step in that direction. Following McGrath (2010), who suggested that successful business model innovations are discovery driven, Hienerth and colleagues suggest that the issue of "runtime effects" of ICT may even prove to be an advantage for firms that experiment with technology like social software. Once deployed and subject to adaptation, social software platforms may evolve in unpredictable directions. McGrath (2010: 254) points out that business model experimentation takes place across and within companies. In this way, the use of platforms such as Facebook may alter

\footnotetext{
${ }^{3}$ For further information about creative commons see http://creativecommons.org/about/.
} 
information flows across and within firms, leading to new opportunities for products and services. Consider Zynga, which produces online games: friends already connected via a social software platform (Facebook) may compete free of charge against each other in online games or acquire certain in-game assets for improved performance, and so on. Cross-promotion activities among games published by Zynga may retain customers or introduce further products and services as the user base grows. The notion of business model portfolios (Sabatier et al., 2010) could be a promising starting point for scholars who want to theorize about complementary strategies for value appropriation using social software.

\section{Contextualizing social software}

From the perspective of changing opportunity structures and informational capabilities, social software is both a tool and mediator in organizational processes. Maintaining balance and achieving specific goals from a managerial point of view entails paying attention to four factors: context, power, ethics, and trust. All these factors deserve more explicit attention in future research to support strategists. First, social software is applied to a specific organizational context or business process. There is a choice of maintaining and supporting an existing context or accommodating work involving social software. Are certain business processes more amenable than others to work practices involving social software? What part do contingencies such as hierarchical information barriers, openness to new organization members, privacy issues, or prior communication patterns play? Does adaptation of the social software change the way it's received in the organization? Does one specific type of work fit better with social software than others? Can strategy processes be opened to outside participants through social software? Strategists should remember that ICT can be heavily customized or designed in-house. Hypothesizing about contingencies and adaptation after adopting technology may pave the way toward creating a favorable context for using social software in a way that can be perceived as successful by both users and management. Case studies of more or less successful implementations of social software along the lines of the contributions in this special issue may help to identify additional context factors.

Second, power struggles are an important element in a number of areas of technology management, from the viewpoint of institutional theory (Hargrave and van de Ven, 2006) as well as from an organizational perspective (Leonardi and Barley, 2010). Proponents of specific technologies form networks (Garud, 2002) or change institutions (Hargrave and van de Ven, 2006) by leveraging and applying legitimacy and framing strategies to supersede their opponents. On a micro scale, actors within one organization or community may dominate others in defining modes of use and work practices involving social software. Leonardi and Barley (2010) suggest that because the construction of meaning and organizational change occurs at multiple levels and phases of ICT implementation, and because its outcome is indeterminate, both human activity and the material features of the technology are significant for the outcome of organizational change. Power struggles may well determine the result of strategic initiatives and challenge strategic management in terms of organizational justice and fairness. A pertinent question in this regard is who is allowed to access information on social software platforms, and for what purpose (for a review see Colquitt et al., 2001).

Third, social software can be perceived as a mediator between groups of users and their respective positions. As a platform for exchange, a filter of information and knowledge, and as facilitator of organizational change, technology inevitably bears values and sides with certain perspectives that may reflect the organization only partially or privilege certain (powerful) individuals. Consumers can become fiercely critical of companies, management, or other employees (Kozinets and Handelman, 2004) and voice criticism even while generally advocating the brand they criticize (Muniz and O'Guinn, 2001). Social software may suddenly create opposing factions that were previously hardly aware of each other. ICT may act as platform for the voices of consumers, users, or developers who loudly and explicitly vent what they could not say before or what went unheard by management. Apart from information flows and employee motivation, such confrontation may require ethical deliberation from the strategist before and during the implementation of social software. Where does learning end in user communities and where does disruption for the company begin? What is the 
correct and appropriate level of respect toward emerging criticism, internal and external? How and when can social software be integrated into the work practice and become a balanced platform, guarantee equal access, or prevent uneven coverage of organizational events? The process by which social software co-evolves with organizations is strategically important, and the opportunities and limitations in managing and mediating co-evolution deserve more attention in future research.

Fourth, the development of social software as a new step in building virtual relations has given a new edge to the issue of trust. It goes without saying that fraudulent behavior, forgery and pretence have not suddenly been spawned by the virtual world and social software. Questions about what is the original and what the copy, not to mention the evaluation of informational goods that are the object of commercial transactions, have given rise to trust issues and highlighted how crucial trust-building mechanisms are to the functioning of markets and communities since the beginning of time. But the development of virtual relations and social software has increased the need for new trustbuilding mechanisms. What is at stake here is the entire range of mechanisms that facilitate interpersonal and interorganizational transactions, given the new conditions for knowledge transactions and exchanges: increasing specialization, increasingly asymmetrical distribution of information and assessment capabilities, ever greater anonymity among interlocutors and ever more opportunities for identity theft. Clearly, new methods need to be devised to "certify" the knowledge circulating through virtual relations within a context where inputs are no longer subject to control.

Contextualizing social software means studying it as both the tool and mediator of organizational change that is triggered, facilitated, and aided by management. "Contextualizing" implies a process of construction, where users form networks, communicate across boundaries and exchange information that may alter their identities and work or question power relationships. That is why contextualizing social software may make power relationships transparent and bring forth ethical issues that researchers can analyze in the nascent structures of organizations. Actionable strategy research gives managers insights into other organizations' experiences of the demands put on them by very sophisticated or recalcitrant users, internal or external to the organization. On the one hand, internal users may undercut hierarchies by way of informal communications via social networks; on the other, managers scan Facebook entries before hiring. Issues pertaining to power relations and ethics run in several directions and call for research that makes these issues transparent and relates them to technology. Such research should also balance the perspectives between management and users, or internal and external company stakeholders.

\section{Co-existing with communities}

Social software plays an instrumental role in facilitating group work and bringing individuals together to form communities. Individuals gather around a shared purpose or attach to other members (Ren et al., 2007) resulting in communities that produce new technology (Sawhey and Prandelli, 2000) or celebrate certain forms of consumption (Muniz and O'Guinn, 2001). Online communities are organizations in their own right that incorporate and govern their work (O'Mahony and Ferraro, 2007), enable joining and specialization of labor (von Krogh et al., 2003), and allow firms to sponsor or regulate work (Shah, 2006; Bonaccorsi et al., 2006; West and O'Mahony, 2005; Capra et al., 2011). The value of social software-enabled communities for business seems obvious in terms of the knowledge they develop and conserve (Brown and Duguid, 2001). There are many types of online community working with various purposes and breeding all sorts of interests and passions. Can companies emulate the best of the governance structures of online communities? And if so, what type of community should serve as a template for learning? Or, more radically, will leadership need to be fundamentally recast in terms of open-ended notions of governance (Hess and Ostrom 2007)? The relationship between firms and online communities is not well understood in organization theory, where outlines became visible for such a relationship to communities located within the perimeters of the firm and operating face-to-face, yet independent and "bottom-up" (Thompson, 2005). The attempt to gain influence in a community may be a struggle; and exerting influence may bring uncertain outcomes for user motivation and user identification with the community's purpose. The study of leadership that bridges and connects firms and communities is an open field for management research. 
Similarly, the discussion of community boundaries raises questions about the purpose of a community, its membership base, and its dynamics. First, purpose may play a central role within the work practice and life context of the individuals who become members of the community (Muniz and O'Guinn, 2001). Communities bear and develop crucial knowledge in organizations (Brown and Duguid, 2001) and there is no reason to believe that communities whose users span organizational boundaries fall short on their ability to develop, protect, and share knowledge (e.g. Lerner and Tirole, 2002; Sawhney and Prandelli, 2000). Purpose and membership seem tightly linked, not only for the ex post definition of what the community is about, but because individuals working on similar issues perceive the need to exchange and learn from their peers and mentors (Lave and Wenger, 1991). While this observation is general and pervades studies of collective action (Oliver, 1993; Ostrom, 1998), it translates into a series of questions regarding the use of social software whose technical implementation is more or less cost-free via the Internet. If firms provide opportunities to interact, individuals sharing similar interests are likely to pick up and exchange information. Importantly, the possible effects of a community on work practices within an organization are a direct consequence of the relatedness and bond that move an individual to join a community in the first place.

Consider the fictitious example of a social software platform (such as LinkedIn or Xing) for the recruitment of management talent within a specific industry. Naturally, prospective talent will rush to become visible on the platform, and so will recruiters. Given an open political and cultural context it becomes easy to see how labor market participants within that industry may join such an emerging community to discuss the firms' strategies, voice their ideas, and challenge each others' ideas. The platform may represent both a labor market opportunity as well as a branding and reputation challenge for participating and sponsoring firms. What policies should accompany the implementation of social software for such a platform? The issues include the eligibility of community membership and the authority to set boundaries, both internal and external. Co-existence with user communities means that authority for such policies is either shared with, or delegated to, members outside the organization, particularly if the company is only a marginal member.

Last, the research issues become even more pronounced when we consider the dynamic properties of community boundaries. There is particular value in search that bridges knowledge domains (Poetz and Prügl, 2010; Laursen and Salter, 2006) and, thus, in community membership that expands in unpredicted ways. On the downside, reputation risks increase because of the nature of social software applications, as we discussed above (Barwise and Meehan, 2010). Research on the dynamic properties of community boundaries is needed, particularly regarding communities that extend beyond the boundaries of one company. Jarvenpaa and Lang (2011) suggest that creating both enabling and constraining boundaries is essential for the sustainability of the communities observed and that these (interdependent) boundaries need to be managed holistically and renegotiated with the community on an ongoing basis. This raises the important question of the link between firm sponsorship and community boundaries, which has not been fully explored. The presence of a company in a user community may not only affect members' motivation and work practices (Shah, 2006), but also the membership dynamics and growth of the community.

\section{Conclusion}

Social software challenges strategic thinking in important ways: the articles in this special issue show strategy practitioners meaningful ways to deploy social software successfully, and strategy researchers which critical challenges deserve more attention. In our introduction we have summarized the open research issues along three dimensions that we believe are critically affected by the massive changes to everyday work in organizations, due to growing use and acceptance of social software within and across companies.

First, value creation and value appropriation can gain momentum through interaction with consumers and users inside and outside the firm. Referring to collaboration with users, Jarvenpaa and Majchrzak (2010) talk of vigilant interaction that involves simultaneous knowledge protection and sharing. The balance between sharing knowledge with consumers and users and protecting 
knowledge assets to appropriate value is subject to experimentation in practice and ongoing research in strategic management and organization theory. Users who had been careless about the rights to their content and innovations (von Hippel, 1988) are becoming more aware of available licenses for their intellectual property (ease of use of creative commons and Open Source licenses) and less sensitive about their privacy (using Twitter and location-based services such as foursquare or LocalUncle). A logic of co-creating strategy may extend the notion of emergent strategy to very active and loyal customers and users outside the company, and create opportunities for strategists who understand and internalize the two perspectives of inside and outside the company.

Second, as a technology, social software challenges not only competitive dynamics in industries but also the structure of organizations. With the increasing digitization of products and services, interaction among consumers and users becomes easier and cheaper. Our behavior as purchasers of e-books depends on the device we use for reading them (mobile or at home, etc.) and recommendations from friends and strangers. The competitive landscape is shaped by what Yoo et al. (2010) call the layered modular architecture, because the choice of a platform-staying with the e-book example, is a choice of both hardware (e-book reader) and social network (recommendations). Thus, social software may appear to be a tool of strategic choice and at the same time a mediator of relationships between the firm and users inside and outside the firm. Frey, Lüthje, and Haag (2011) make the point that empowering and restricting the user goes hand-in-hand with receiving substantive user contributions. This balance is also a question of power relations; the design and implementation of social software needs to take into account that these relations can substantially alter or disrupt organizational processes (Leonardi, 2007).

Third, communities grow and build on social software applications that enable users and consumers to interact. Two choices impact strategic thinking: leadership and boundaries. To what extent should management lead a community and to what extent should strategists influence the extent of growth and influence of the community? Again, both decisions are constrained and enacted as part of a balancing act that makes the community possible in the first place. A logic of co-existence can guide strategic thinking when deciding about sponsoring a community by setting up social software infrastructures and sharing knowledge. The contribution of Denyer and colleagues in this issue alerts management to the pitfalls this can entail. The same logic may guide leadership that can be shared or distributed across community members who stand out independently of, and possibly outside, the firm.

A strategic approach to social software should start with the insight that empowering creative, independent individuals implies indeterminate and uncertain reactions and creations in support of, or in opposition to, management's original thinking. New business opportunities abound and an experimental approach to strategy (McGrath, 2010) may be guided by the signposts erected by successful companies, who maintain long-term relationships with their users. A number of these are described and analyzed in this special issue.

\section{Acknowledgements}

This research project received support from the Swiss National Science Foundation (Grant 100014_125513). The guest editors would like to thank the editor-in-chief James Robins and former editor Charles Baden-Fuller for their continued support of this special issue. We would also like to thank all the authors and reviewers who submitted and evaluated manuscripts: without their support this issue would not have been possible.

\section{References}

Allen, Christopher, 2004. Tracing the evolution of social software. http://www.lifewithalacrity.com/2004/10/ tracing_the_evo.html.

Arakji, Reina, Lang, Karl R., Fall 2007. Digital consumer networks and producer-consumer collaboration: innovation and product development in the video game industry. Journal of Management Information Systems 24 (4), 199-224. 
Baldwin, C.Y., Clark, K.B., 2006. "The architecture of participation: does code architecture mitigate free riding in the open source development model?”. Management Science 52 (7) (July), 1116-1127.

Barley, S.R., 1986. "Technology as an occasion for structuring - evidence from observations of CT scanners and the social-order of radiology departments". Administrative Science Quarterly 31 (1) (March), 78-108.

Barwise, P., Meehan, S., 2010. "The one thing you must get right when building a brand". Harvard Business Review 88 (12) (December), 80-84.

Benkler, Y., 2002. "Coase's penguin, or, Linux and The Nature of the Firm". Yale Law Journal 112 (3) (December), 369-446.

Bonaccorsi, A., Giannangeli, S., Rossi, C., 2006. "Entry strategies under competing standards: Hybrid business models in the open source software industry". Management Science 52 (7), 1085-1098.

Brynjolfsson, E., Saunders, A., 2009. Wired for innovation: how information technology is reshaping the economy. MIT Press.

Brown, J.S., Duguid, P., 2001. "Knowledge and organization: a social-practice perspective". Organization Science 12 (2) (April), 198-213.

Capra, E., Francalanci, C., Merlo, F., Rossi-Lamastra, C., 2011. "Firms' involvement in open source projects: a trade-off between software structural quality and popularity". Journal of Systems and Software 84 (1) (January), 144-161.

Casadesus-Masanell, R., Ghemawat, P., 2006. "Dynamic mixed duopoly: a model motivated by Linux vs. Windows". Management Science 52 (7), 1072.

Chesbrough, Henry William, 2003. Open innovation: the new imperative for creating and profiting from technology. Harvard Business Press.

Ciborra, C.U., 1996. "The platform organization: recombining strategies, structures, and surprises". Organization Science 7 (2) (April), 103-118.

Collier, Benjamin, Burke, Moira, Kittur, Niki, Kraut, Robert, 2010. Promoting Good Management: Governance, Promotion, and Leadership in Open Collaboration Communities. ICIS 2010 Proceedings (January 1). http://aisel.aisnet.org/icis2010_submissions/220.

Colquitt, J.A., Conlon, D.E., Wesson, M.J., Porter, C.O.L.H., Ng, K.Y., 2001. "Justice at the millennium: a meta-analytic review of 25 years of organizational justice research". Journal of Applied Psychology 86 (3) (June), 425-445.

Cooke, M., Buckley, N., 2008. "Web 2.0, social networks and the future of market research". International Journal of Market Research 50 (2), 267-292.

Culnan, M.J., McHugh, P.J., Zubillaga, J.I., 2010. "How large U.S. companies can use Twitter and other social media to gain business value". MIS Quarterly Executive 9 (4) (December), 243-259.

da Cunha, João Vieira, Orlikowski, Wanda J., 2008. "Performing catharsis: The use of online discussion forums in organizational change". Information and Organization 18 (2), 132-156.

Dahlander, L., 2007. "Penguin in a new suit: a tale of how de novo entrants emerged to harness free and open source software communities". Industrial and Corporate Change 16 (5) (October), 913-943.

Dahlander, L., Magnusson, M., 2008. "How do firms make use of open source communities?" Long Range Planning 41 (6) (December), 629-649.

Dahlander, L., Wallin, M.W., 2006. "A man on the inside: unlocking communities as complementary assets". Research Policy 35 (8) (October), 1243-1259.

Dellarocas, C., Wood, C.A., 2008. "The sound of silence in online feedback: estimating trading risks in the presence of reporting bias". Management Science 54 (3) (March), 460-476.

Denyer, D., Parry, E., Flowers, P., 2011. "Social", "open" and "participative"? Exploring personal experiences and organizational effects of Enterprise2.0 use. Long Range Planning 44 (5-6), 375-396.

DeSanctis, G., Poole, M.S., 1994. "Capturing the complexity in advanced technology use - adaptive structuration theory”. Organization Science 5 (2), 121-147.

Faulkner, P., Runde, J., 2009. "On the identity of technological objects and user innovation in function". Academy of Management Review 34 (3) (July), 442-462.

Fleming, L., Waguespack, D.M., 2007. "Brokerage, boundary spanning, and leadership in open innovation communities”. Organization Science 18 (2) (April), 165-180.

Franke, Nikolaus, Schreier, Martin, Kaiser, Ulrike, 2010. "The 'I Designed It Myself' effect in mass customization". Management Science 56 (1) (January 1), 125-140.

Fredberg, T., 2009. “Organising customers: learning from Big Brother". Long Range Planning 42 (3) (June), 320-340.

Frey, K., Lüthje, C., Haag, S., 2011. Whom Attract to Open Innovation Platforms? The Role of Knowledge Diversity and Motivation. Long Range Planning should firms 44 (5-6), 397-420. 
Fuchs, Christoph, Schreier, Martin, 2011. "Customer empowerment in new product development". Journal of Product Innovation Management 28 (1) (January), 17-32.

Füller, J., Faullant, R., Matzler, K., 2010. “Triggers for virtual customer integration in the development of medical equipment - From a manufacturer and a user's perspective”. Industrial Marketing Management 39 (8) (November), 1376-1383.

Garud, R., 2002. "Institutional entrepreneurship in the sponsorship of common technological standards: The case of Sun Microsystems and Java". The Academy of Management journal 45 (1), 196.

Haefliger, S., Reichen, P., Jager, P.M., von Krogh, G., 2009. "Modding as rating behavior in virtual communities: the case of Rooster teeth productions". Lecture Notes in Computer Science 5621, 197-206.

Haefliger, S., Jäger, P., von Krogh, G., 2010. “Under the radar: industry entry by user entrepreneurs”. Research Policy 39, 1198-1213.

Hargrave, T.J., van de Ven, A., 2006. “A collective action model of institutional innovation”. The Academy of Management Review 31 (4), 864.

Henkel, Joachim, 2006. "Selective revealing in open innovation processes: the case of embedded Linux". Research Policy 35 (7) (September), 953-969.

Hertel, Guido, Niedner, Sven, Herrmann, Stefanie, 2003. "Motivation of software developers in open source projects: an internet-based survey of contributors to the Linux Kernel”. Research Policy 32 (7) (July), 1159-1177.

Hess, C., Ostrom, E., 2007. Understanding knowledge as a commons. MIT Press, Cambridge, MA.

Hienerth, C., Keinz, P., Lettl, C., 2011. Exploring the nature and implementation process of IT-based usercentric business models. Long Range Planning.

Ho, Joanna L.Y., Wu, Anne, Xu, Sean Xin, 2011. "Corporate governance and returns on information technology investment: evidence from an emerging market". Strategic Management Journal 32 (6) (June 1), 595-623.

Hustad, E., Teigland, R., 2008. "Implementing social networking media and Web 2.0 in multinationals: Implications for knowledge management". Proceedings of the 9th European Conference on Knowledge Management, 323-331.

Jarvenpaa, S.L., Lang, K.R., 2011. Boundary Management in Online Communities: Case Studies of the Nine Inch Nails and ccMixter Music Remix Sites. Long Range Planning.

Jarvenpaa, S., Majchrzak, A., 2010. "Vigilant Interaction in Knowledge Collaboration: Challenges of Online User Participation Under Ambivalence". Information Systems Research 21 (4), 773-784.

Jeppesen, Lars Bo, Lakhani, Karim R., 2010. "Marginality and problem-solving effectiveness in broadcast search". Organization Science 21 (September), 1016-1033.

Jeppesen, L.B., Frederiksen, L., 2006. "Why do users contribute to firm-hosted user communities? The case of computer-controlled music instruments". Organization Science 17 (1) (February), 45-63.

Kaplan, Andreas M., Haenlein, Michael, 2010. "Users of the world, unite! The challenges and opportunities of social media". Business Horizons 53 (1), 59-68.

Kerner, S.M., 2010. You Can't Control Linux. CIO Update. http://www.cioupdate.com/features/article.php/ 3876581/You-Cant-Control-Linux.htm.

Kling, R., Scacchi, W., 1982. “The web of computing: computer technology as social organization”. Advances in computers 21,1 .

Kohler, T., J. Fueller, K. Matzler, and D. Stieger. 2011. "Co-Creation in Virtual Worlds: The Design of the User Experience.” MIS Quarterly. Forthcoming.

Kozinets, R.V., 2002. "The field behind the screen: Using netnography for marketing research in online communities". Journal of Marketing Research 39 (1) (February), 61-72.

Kozinets, R., Handelman, J., 2004. "Adversaries of consumption: consumer movements, activism, and ideology". The Journal of consumer research 31 (3), 691-704.

Kuk, George, 2006. "Strategic interaction and knowledge sharing in the KDE developer mailing list". Management Science 52 (7) (July 1), 1031-1042.

Lakhani, K.R., von Hippel, E., 2003. "How open source software works: 'free' user-to-user assistance". Research Policy 32 (6) (June), 923-943.

Lamastra, C.R., 2009. "Software innovativeness. A comparison between proprietary and free/open source solutions offered by Italian SMEs”. R \& D management 39 (2), 153.

Lang, K.R., Shang, Di, Vragov, Roumen, December 2009. Designing markets for co-production of digital culture products. Decision Support Systems 48 (1), 33-45.

Laursen, K., Salter, A., 2006. "Open for innovation: The role of openness in explaining innovation performance among UK manufacturing firms”. Strategic Management Journal 27 (2) (February), 131-150. 
Lave, J., Wenger, E., 1991. Situated Learning. Cambridge University Press.

Lee, G.K., Cole, R.E., 2003. "From a firm-based to a community-based model of knowledge creation: the case of the Linux kernel development". Organization Science 14 (6) (December), 633-649.

Leidner, D., Preston, D., Chen, D., 2010. "An examination of the antecedents and consequences of organizational ICT innovation in hospitals". Journal of strategic information systems 19 (3), 154-170.

Leonardi, P.M., Barley, S.R., 2010. "What's under construction here? Social action, materiality, and power in constructivist studies of technology and organizing". Academy of Management Annals 4, 1-51.

Leonardi, P., 2007. "Activating the informational capabilities of information technology for organizational change". Organization science 18 (5), 813-831.

Leonardi, P., 2008. "Indeterminacy and the discourse of inevitability in international technology management". The Academy of Management review 33 (4), 975-984.

Lerner, J., Tirole, J., 2002. "Some simple economics of open source". The Journal of industrial economics 50 (2), 197-234.

Lerner, J., Tirole, J., 2005. "The economics of technology sharing: Open source and beyond". Journal of Economic Perspectives 19 (2), 99-120.

Markus, M. Lynne, 1983. "Power, politics, and MIS implementation". Communications of the ACM 26 (June), 430-444.

Markus, M., 2007. “The governance of free/open source software projects: monolithic, multidimensional, or configurational?". Journal of Management and Governance 11 (2) (May 1), 151-163.

Markus, M. Lynne, Robey, Daniel, 1988. "Information technology and organizational change: causal structure in theory and research". Management Science 34 (5) (May 1), 583-598.

Markus, M.L., Silver, M.S., 2008. "A foundation for the study of IT effects: a new look at DeSanctis and Poole's concepts of structural features and spirit". Journal of the Association for Information Systems 9 (10), 609-632.

Martins, Luis L., Gilson, Lucy L., Travis Maynard, M., 2004. "Virtual teams: what do we know and where do we go from here?". Journal of Management 30 (6) (November), 805-835.

McGrath, R.G., 2010. "Business models: a discovery driven approach". Long Range Planning 43 (2-3) (June), 247-261.

Mintzberg, H., 1978. "Patterns in strategy formation”. Management Science 24 (9), 934-948.

Moon, Jae Yun, Sproull, Lee, 2000. “Essence of distributed work: The case of the Linux kernel”. First Monday 5 (11).

Muniz, A.M., O'Guinn, T.C., 2001. "Brand community”. Journal of Consumer Research 27 (4) (March), 412-432.

O'Mahony, S., Bechky, B.A., 2008. "Boundary organizations: enabling collaboration among unexpected allies". Administrative Science Quarterly 53 (3) (September), 422-459.

O’Mahony, Siobhán, 2003. "Guarding the commons: how community managed software projects protect their work". Research Policy 32 (7) (July), 1179-1198.

O’Mahony, S., Ferraro, F., 2007. "The emergence of governance in an open source community". Academy of Management Journal 50 (5) (October), 1079-1106.

O'Reilly, Tim, 2005. What is Web 2.0?. http://oreilly.com/web2/archive/what-is-web-20.html.

Oliver, Pamela E., 1993. "Formal models of collective action". Annual Review of Sociology 19, 271-300.

Orlikowski, W.J., 1992. "The duality of technology - rethinking the concept of technology in organizations". Organization Science 3 (3), 398-427.

Orlikowski, W.J., Scott, S.V., 2008. "Sociomateriality: challenging the separation of technology, work and organization". Academy of Management Annals 2, 433-474.

Ostrom, Elinor, 1998. "A behavioral approach to the rational choice theory of collective action: presidential address, American political science association, 1997". The American Political Science Review 92 (1) (March 1), 1-22.

Pauleen, D.J., Yoong, P., 2001. "Relationship building and the use of ICT in boundary-crossing virtual teams: a facilitator's perspective". Journal of Information Technology 16 (4) (December), 205-220.

Perrow, C., 1967. "A framework for the comparative analysis of organizations". American Sociological Review $32(2), 194$.

Poetz, M.K., Prügl, R., 2010. "Crossing domain-specific boundaries in search of innovation: exploring the potential of pyramiding”. Journal of Product Innovation Management 27 (6) (November), 897-914.

Powell, T.C., DentMicallef, A., 1997. "Information technology as competitive advantage: The role of human, business, and technology resources". Strategic Management Journal 18 (5) (May), 375-405.

Raymond, E., 1999. "The cathedral and the bazaar". Knowledge, Technology \& Policy 12 (3), 23-49.

Ren, Y.Q., Kraut, R., Kiesier, S., 2007. "Applying common identity and bond theory to design of online communities”. Organization Studies 28 (3) (March), 377-408. 
Rolland, K.H., Monteiro, E., 2007. When 'perfect' integration leads to increasing risks: the case of an integrated information system in a global company. In: Ciborra, C., Hanseth, O. (Eds.), Risk, complexity and ICT. Edwar Elgar Publishing.

Rosenkopf, L., Metiu, A., George, V.P., 2001. "From the bottom up? Technical committee activity and alliance formation”. Administrative Science Quarterly 46 (4) (December), 748-772.

Sabatier, V., Mangematin, V., Rousselle, T., 2010. "From recipe to dinner: business model portfolios in the European biopharmaceutical industry". Long Range Planning 43 (2-3) (June), 431-447.

Sampler, J.L., 1998. "Redefining industry structure for the information age". Strategic Management Journal 19 (4) (April), 343-355.

Sawhney, M., Prandelli, E., 2000. "Communities of creation: managing distributed innovation in turbulent markets". California Management Review 42 (4), 24.

Schau, H.J., Gilly, M.C., 2003. "We are what we post? Self-presentation in personal Web space". Journal of Consumer Research 30 (3) (December), 385-404.

Shah, S., 2006. "Motivation, governance, and the viability of hybrid forms in open source software development". Management Science 52 (7), 1000-1014.

Shirky, Clay, 2005. A group is its own worst enemy. In The Best Software Writing I: Selected and introduced by Joel Spolsky. Apress. http://www.springerlink.com/content/x768266j5m112474/.

Spaeth, S., Stuermer, M., von Krogh, G., 2010. "Enabling knowledge creation through outsiders: towards a push model of open innovation". International Journal of Technology Management 52 (3-4), $411-431$.

Sproull, Lee, Kiesler, Sara, 1986. "Reducing social context cues: electronic mail in organizational communications". Management Science 32 (11) (November 1), 1492-1512.

Stam, W., 2009. "When does community participation enhance the performance of open source software companies?". Research Policy 38 (8) (October), 1288-1299.

Stewart, K.J., Ammeter, A.P., Maruping, L.M., 2006. "Impacts of license choice and organizational sponsorship on user interest and development activity in open source software projects". Information Systems Research 17 (2) (June), 126-144.

Stuermer, M., Spaeth, S., von Krogh, G., 2009. "Extending private-collective innovation: a case study". R \& D Management 39 (2) (March), 170-191.

Thompson, M., 2005. "Structural and epistemic parameters in communities of practice". Organization Science 16 (2) (April), 151-164.

Tippins, M.J., Sohi, R.S., 2003. "ICT competency and firm performance: Is organizational learning a missing link?". Strategic Management Journal 24 (8) (August), 745-761.

Vaughan-Nichols, S., 2009. "If IBM owns Java". JavaWorld. April 3. http://www.javaworld.com/javaworld/jw04-2009/jw-04-if-ibm-owns-java.html.

von Hippel, Eric, 1988. "Sources of Innovation". MIT Press.

von Hippel, Eric, 2007. "Horizontal innovation networks-by and for users". Industrial and Corporate Change 16 (2) (April 1), 293-315.

von Hippel, E., von Krogh, Georg F., 2003. "Open source software and the 'private-collective' innovation model: Issues for organization science”. Organization Science 14 (2), 209-223.

von Krogh, G., 2002. "The communal resource and information systems". Journal of Strategic Information Systems 11 (2) (June), 85-107.

von Krogh, G., Haefliger, S., 2010. "Opening up design science: The challenge of designing for reuse and joint development". Journal of Strategic Information Systems 19, 232-241.

von Krogh, Georg F., Spaeth, Sebastian, Lakhani, K.R., 2003. "Community, joining, and specialization in open source software innovation: a case study”. Research Policy 32 (7), 1217-1241.

von Krogh, Georg, von Hippel, Eric, 2006. "The promise of research on open source software". Management Science 52 (7) (July), 975-983.

Wagner, E.L., Newell, S., Piccoli, G., 2010. "Understanding project survival in an ES environment: a sociomaterial practice perspective". Journal of the Association for Information Systems 11 (5), 276-297.

West, Joel, Gallagher, Scott, 2006. "Challenges of open innovation: the paradox of firm investment in opensource software”. R\&D Management 36 (3) (June 1), 319-331.

West, Joel, O'Mahony, Siobhan, 2005. Contrasting community building in sponsored and community founded open source projects. In: Hawaii International Conference on System Sciences, vol. 7: 196c. IEEE Computer Society, Los Alamitos, CA, USA. 
Wiertz, C., de Ruyter, K., 2007. "Beyond the call of duty: why customers contribute to firm-hosted commercial online communities". Organization Studies 28 (3) (March), 347-376.

Wirtz, B.W., Schilke, O., Ullrich, S., 2010. "Strategic development of business models implications of the web 2.0 for creating value on the internet". Long Range Planning 43, 2-3 (June), 272-290.

Yamauchi, Yutaka, Yokozawa, Makoto, Shinohara, Takeshi, Ishida, Toru, 2000. Collaboration with lean media: how open-source software succeeds. In: Proceedings of the 2000 ACM conference on Computer supported cooperative work, pp. 329-338. ACM, Philadelphia, Pennsylvania, United States.

Yoo, Y., Henfridsson, O., Lyytinen, K., 2010. "The new organizing logic of digital innovation: an agenda for information systems research". Information Systems Research 21 (4), 724-735.

Young, Robert, Rohm, Wendy Goldman, 1999. Under the Radar: How Red Hat Changed the Software Business - and Took Microsoft by Surprise. Coriolis Value. http://portal.acm.org/citation.cfm?id=554943.

\section{Biographies}

Stefan Haefliger (Dr. oec., University of St. Gallen) works as a researcher and lecturer at the Department of Management, Technology, and Economics at ETH Zurich. His research and teaching focuses on co-creation strategies as well as knowledge reuse and design in innovation processes. Stefan serves as an associate editor for Long Range Planning and his research has appeared in Management Science, Research Policy, and the Journal of Strategic Information Systems. Department of Management, Technology, and Economics MTEC, ETH Zurich, Kreuzplatz 5, 8032 Zürich, Switzerland Tel: +41 446328776 email: shaefliger@ethz.ch.

Eric Monteiro (Dr. scient., Univ. of Oslo) is professor in Information Systems at the Norwegian University of Science and Technology in the Department of Computer and Information Sciences. His research interests are on ICT-based modes of collaboration, knowledge sharing and user-led innovation. He has published in journals such as MIS Quarterly, Information and Organization, The Information Society and Computer Supported Cooperative Work. He serves as senior editor for Information Systems Research and is editorial board member of several journals.

Department of Computer and Information Sciences, Norwegian University of Science and Technology NTNU, 7491 Trondheim, Norway

Dominique Foray (Ph.D., University Lumière, Lyon) is professor at the Ecole Polytechnique Fédérale de Lausanne (EPFL) and is the Director of the Chair of Economics and Management of Innovation at the College of Management of EPFL. He is a member of the Swiss National Research Council and has chaired the Group of Experts "Knowledge for Growth" of the European Commission. He has published in journals such as Research Policy, Industry and Corporate Changes, Evolutionary Economics, Economics of Innovation and New Technology, International Journal of Industrial Organization, etc. He has written numerous books on the economics of innovation and technology policy; among them "The Economics of Knowledge" at MIT Press. EPFL, CDM - CEMI, Odyssea 1.16, Station 5, CH - 1015 Lausanne, Switzerland

Georg von Krogh (Ph.D., Norwegian University of Technology and Natural Science) is a professor at ETH Zurich where he holds the Chair of Strategic Management and Innovation. Georg specializes in competitive strategy, technological innovation, and knowledge management. His work has been published in leading journals including Management Science, Organization Science, Research Policy, Strategic Management Journal, and Harvard Business Review. He is a senior editor for Organization Studies, and an editorial board member of a number of journals. Department of Management, Technology, and Economics MTEC, ETH Zurich, Kreuzplatz 5, 8032 Zürich, Switzerland 